\title{
A Novel Teaching Approach for Mobile Internet-Based Collaborative Knowledge Construction in "Teaching Management"
}

\author{
https://doi.org/10.3991/ijet.v16i12.23323 \\ Sheng Zhang \\ Bangkok Thonburi University, Bangkok, Thailand \\ zhangsheng20250163. com
}

\begin{abstract}
With the development of education, teaching, as the basic and central work at school, is conducted most frequently with the largest workload. In simple words, teaching management for the purpose of the management of teaching work is an essential content of school management, as well as a basic activity of school leaders. Therefore, more than just the basis and guarantee for the normal operation of school teaching, teaching management course plays a critical role in teacher growth and education reform, has great significance for schools. However, problems in current teaching management courses, such as lack of teacher-student interaction, single teaching content, and simple teaching methods have hindered students to develop interest in learning, and impede teachers to give full play to their educational personality. In this paper, a new collaborative knowledge construction teaching approach was applied in mobile Internet technology environment, and a blended teaching model of students' online autonomous collaborative learning before class, knowledge internalization in class, and leak filling after class was proposed. At the same time, the personalized recommendation technology based on collaborative filtering algorithm was applied. Firstly, mobile terminal core information was collected from the mobile Internet learning platform for preprocessing, and then the processed data were identified by the collaborative filtering algorithm to recognize the intrusion data, thereby realizing the quick screening and accurate pushing of learning resources. It was found from the teaching practice that this model can effectively enhance students' interest in learning, improve learning effects and independent innovation capabilities.
\end{abstract}

Keywords - Mobile internet; teaching management; collaborative knowledge; filtering algorithm

\section{Introduction}

With the high-speed development of modern science and technology, new media technology can be reasonably used for imparting knowledge to others by means of information technology, which is a special advantage of new media available for integration and usage in college teaching management course to enhance overall 
quality of college teaching management education. With the advent of the era of Internet technology big data, because of COVID-19 at the end of 2019, to safeguard the lives of teachers and students, colleges and universities were postponed. In order not to affect students' studies, a variety of online teaching platforms were used for personalized online teaching [1]. The subject of teaching management was no exception. However, due to some teachers' insufficient understanding of the new Internet-based teaching model, online management teaching could not fully manifest its individualization. Without in-depth analysis of student interaction reflected on the platform, the precision teaching could not be fully manifested [2]. In the meantime, in terms of the teacher's teaching model, a relatively complete system has not yet been established, the interaction with students was not enough during teaching, and due to the insufficient data information, the superiority of the Internet teaching model could not be reflected. In view of above problems, this research is focused on the course reform of teaching management course reform through new network technology, combined with collaborative knowledge construction teaching approach. At the same time, personalized recommendation technology based on collaborative filtering algorithm was used to accurately screen a large number of rich video resources on the Internet, to create a new type of Internet teaching management teaching environment, and to establish a network public teaching management teaching platform by using the advantages of the timely and rapid Internet information dissemination, in hope of providing a new idea and reference for teaching management course reform.

\section{State of the Art}

Educational management, a highly practical major under the category of management requires to combine theory with practice to guide students to closely integrate management theory with practice, and learn how to apply management theory to management practice, thereby further deepening their understanding of theory [3]. Therefore, it is necessary to select a rational and scientific course method. For example, during the teaching management course of Georgia University in the United States, "daily readings" before class are required for graduate students. Teachers attach great importance to graduate students' pre-class preparation, classroom participation, and practical operations, adopt classroom presentations and discussions, case analysis and reflection, and practical operation, and other teaching forms. The graduate students' classroom performance determines their performance [4]. This method is conductive to students' better understanding of new course knowledge. The education management courses offered by UK universities are standardized according to evaluation standards by using visual guidance methods for supervision and management rather than a unified outline or textbooks. Apart from a brief introduction of thousands of words, there is a 50,000-word "course manual", consisting of 9 parts including introduction, goals and expectations, and a list of searchable websites [5]. Such teaching training mode is designed to cultivate students' practical ability. The teaching management course offered by Monash University in Australia emphasizes scientificity and flexibility, focuses on self-directed study, 
adopts diversified teaching methods, flexible training paths and curriculum elective modes, and empirical research methods, attaches greater importance to the pragmatism and interaction of the teaching and learning process. The education management course offered by Nanyang Technological University in Singapore pays attention to cultivate education leaders' management idea [6]. As teachers attach great importance to students' classroom presentations and practical reflections during the teaching process, it can substantially enhance students' practical application skills. Das et al. [7] proposed to apply the flipped classroom teaching approach to management teaching. A set of pre-class learning videos suitable for the management course was designed before class for students' preview and students were encouraged to acquire knowledge before lectures and seminars. The research results showed that such teaching approach is conductive to the improvement of students' learning effect and learning satisfaction. Strang et al. [8] proposed that this study was to investigate if undergraduate students could assess peer work in a school of Business Management course which involved several long essay-type reports. A key challenge was the volume of grading since there were three written assignments spread throughout the course. The secondary goal was to explore if the learning management system (LMS) could facilitate the peer assessment process and if it could calculate a fair grade representing the quality of peer assessment work. The results proved that this peer review teaching method can enhance students' learning initiative.

In China, the education management course is set as the basic course for the education major, and it is also the main course for the public service management major. Some scholars have proposed that the education management course teaching requires to pursue knowledge integrity while focusing on guiding students to use teaching materials, to learn, give full play to the teacher-led and student-based attribute, and cultivate students' ability to solve practical problems in an open teaching environment. Feng [9] proposed an education management system software based on computer operating system, and added related teaching content applications to the system through virtual technology, and finally created the desired image file and designed it as online course learning resources. It was found from teaching practice that such learning resource could yield satisfactory teaching effect. Li [10] integrated case teaching by adopting creative teaching model and concept, and conducted a specific analysis of the application of this teaching mode in teaching management course. It was proved by the results that it can enhance teaching efficiency and learning quality. Due to the outbreak of COVID-19 in 2019, many colleges and universities were postponed so that online teaching was adopted, which can break through the limitations of time and space, create conditions for students to learn anytime and anywhere. Then, a series of online teaching reforms were carried out on education management course. Tao et al. [11] proposed that it is necessary to draw mature campus network resources for online teaching management, and design a teaching platform specifically applied to teaching management by means of mobile Internet communication technology, so as to promote the sharing and improvement of teaching materials. Zhang [12] pointed out the importance of combining mobile technology and teaching mode under the current Internet + education background, proposed to, and adopt mobile Internet-based Chaoxing Learning Communication 
platform according to the characteristics of school management courses to satisfy students' diverse learning demand and stimulate their learning enthusiasm. However, also literature pointed out that there still exist some deficiencies in the current education management course, such as the single teaching method, which is manifested as lecture-oriented teaching and guidance, resulting in low teaching efficiency, as well as the unidirectional teaching process, resulting in imbalanced and insufficient interaction between students and teachers [13]. Students need to spend numerous energy to acquire new knowledge, which hinders their innovative thinking to a certain extent.

To solve this problem, this paper analysed and summarized the existing teaching models, and finally established a new collaborative knowledge construction teaching approach based on Internet technology, which is applicable to education management course. Secondly, mobile technology-based mobile phone interactive teaching approach was adopted to conduct teaching design via mobile phone, thereby ultimately realizing the goal of knowledge construction for learners. At the same time, the learning system was designed by innovatively using collaborative filtering algorithm for rapid screening and accurate pushing of learning resources. In the meantime, the model was applied to education management course practice for analysis. Then, its strengths and weaknesses were summarized to provide certain reference for teaching staff.

\section{Internet-Based Online Collaborative Knowledge Construction Teaching Model Design}

\subsection{Online collaborative knowledge construction teaching model design}

It can be seen from Figure 1 that online collaborative knowledge construction is aimed at fully stimulating students' subjective initiative, allowing them to make independent choice to learn and establish personalized knowledge system for a better understanding and application of knowledge. Before class, students first set their own learning goals, and answer questions according to teacher's explanation in the class to enhance their knowledge system. At the beginning of the course, the teacher should first guide students into the context of the course, and then ask students to analyze the scenario independently; during students' exploration, teacher should provide some tips at the appropriate time to inspire their creative thinking. At the beginning, teacher can provide tips more frequently and then reduce the frequency after guiding the student into the scenario; finally, the student can achieve the teaching goal under the state of independent thinking. Afterwards, students are divided into groups for ingroup discussion and experience exchange for collaborative knowledge construction. 


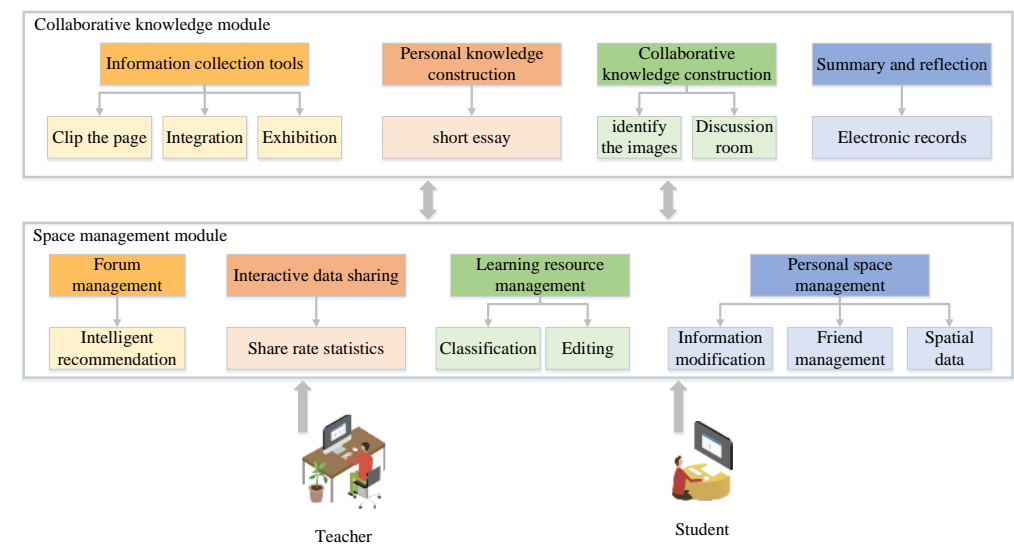

Fig. 1. Diagram of online collaborative knowledge construction

\subsection{Establishment of educational management mobile Internet teaching based on collaborative filtering algorithm}

The main idea of user-based nearest neighbour recommendation is: First, the input rating data set and the current user ID were considered as input to discover other users with similar preferences in the past, who are called peer users or nearest neighbor; then, for each product $\mathrm{p}$ never seen by the current user, the score of the product $\mathrm{p}$ was predicted by using the user's neighbor; finally, the TopN products with the highest product scores were selected and recommended to the current user. In case of similar preferences in the past, the user would have similar preferences in the future, which would not change with time. The correlation between two users was expressed by Pearson/Pearson correlation coefficient, with a value range of $[-1,+1]$. -1 indicated strong negative correlation, +1 indicated strong positive correlation, and 0 indicated no correlation.

$$
\ell_{u, v}=\frac{\sum_{p \in P_{u, v}}\left(r_{u, p}-\bar{r}_{u}\right)\left(r_{v, p}-\bar{r}_{v}\right)}{\sqrt{\sum_{p \in P_{u, v}}\left(r_{u, p}-\bar{r}_{u}\right)^{2}} \sqrt{\sum_{p \in P_{u, v}}\left(r_{v, p}-\bar{r}_{v}\right)^{2}}}
$$

As required by the application of Pearson correlation coefficient, when the standard deviations of the two variables were not zero, the correlation coefficient could be defined. The usage scenarios are as follows: there exists a linear relation between two variables and both are continuous data; the totality of the two variables is normal distribution or solving the normal unimodal distribution; the observation values of the two variables are in pairs, and each pair of observations is mutually contradictory; when the correlation between user a and other users is calculated, the most similar $\mathrm{N}$ neighbor users can be selected to calculate the score prediction value for the item $\mathrm{p}(\mathrm{N}$ neighbor users have score values for the item $\mathrm{p}$ ). 


$$
\operatorname{pred}(u, p)=\bar{r}_{u}+\frac{\sum_{v \in N} \ell_{u, v} *\left(r_{v, p}-\bar{r}_{v}\right)}{\sum_{v \in N} \ell_{u, v}}
$$

The idea of item-based nearest neighbor recommendation is based on the similarity between items, instead of the prediction of the score value based on the similarity between users. In the item-based nearest neighbor recommendation algorithm, cosine similarity was used to calculate the similarity value between two items. The similarity value range is $[0,1]$. The closer the value is to 1 , the more similar between both.

$$
\ell_{\vec{a}, \vec{b}}=\frac{\vec{a} \mid \vec{b}}{|\vec{a}| *|\vec{b}|}
$$

Due to the difference between the average user ratings not considered, the improved similarity formula is generally used to calculate the similarity by subtracting the average from the rating value. The value range of the improved cosine similarity formula is [-1,1], same as Pearson's correlation coefficient.

$$
\ell_{a, b}=\frac{\sum_{u \in U}\left(r_{u, a}-\bar{r}_{u}\right)\left(r_{u, b}-\bar{r}_{u}\right)}{\sqrt{\sum_{u \in U}\left(r_{u, a}-\bar{r}_{u}\right)^{2}} \sqrt{\sum_{p \in P_{u, v}}\left(r_{u, b}-\bar{r}_{u}\right)^{2}}}
$$

In the personal center function module, apart from the basic personal information query and revision, personal playback history, and video collection records can be checked. In the personalized recommendation module, the characteristics of learners can be actively collected and analyzed by the Internet mobile teaching system, video materials that learners are interested are recommended to provide personalized services. The personalized recommendation module is the core module of the Internet mobile teaching system designed in this paper. By what means and rules to recommend learners interesting materials are the difficulties. To accurately recommend video materials that satisfy learners' personal preferences, an Internet mobile teaching system based on collaborative filtering algorithm was designed in this paper. The specific algorithm steps are described as follows:

- Step 1: $L=\left\{l_{1}, l_{2}, \cdots, l_{i}, \cdots l_{N}\right\}$ was set as an aggregate of learners; $M=\left\{m_{1}, m_{2}, \cdots, m_{i}, \cdots m_{n}\right\}$ was set as an aggregate of video data; the interest degree function $g_{i, m}$ could be used to predict the score of user $l_{i}$ on the video $m_{j}$.

- Step 2: the similarity between learners was calculated by correlation similarity method, expressed as $\operatorname{sim}(x, y)$, and the specific equation is described as follows: 


$$
\operatorname{sim}(x, y)=\frac{\sum_{m \in m_{y,}}\left(g_{x, m}-\bar{g}_{x}\right)\left(g_{y, m}-\bar{g}_{y}\right)}{\sqrt{\sum_{m \in m_{y}}\left(g_{x, m}-\bar{g}_{x}\right)^{2} \sum_{m \in m_{y y}}\left(g_{y, m}-\bar{g}_{y}\right)^{2}}}
$$

Wherein, $x \in L, y \in L ; g_{x, m} 、 g_{y, m}$ are the scores of the learner $\mathrm{x}$ and learner $\mathrm{y}$ on the video $\mathrm{m} ; \bar{g}_{x}, \bar{g}_{y}$ are the average scores respectively, and

$$
\bar{g}_{x}=\left(\frac{1}{\left|m_{x}\right|}\right) \sum_{m \in m_{x}} g_{x, m}, \bar{g}_{y}=\left(\frac{1}{\left|m_{y}\right|}\right) \sum_{m \in m_{y}} g_{y, m}
$$

Wherein,

$m_{x}=\left\{m \in M \mid g_{x, m} \neq 0\right\}, m_{y}=\left\{m \in M \mid g_{y, m} \neq 0\right\} ; m_{x y}$ is the aggregate of videos scored by learner $\mathrm{x}$ and learner $\mathrm{y}$.

- Step 3: learners with high similarity to the target learner $\mathrm{x}$ were selected as the aggregate of neighbor learners, expressed as $\hat{L}$, the score of learner $\mathrm{x}$ on his unscored video $\mathrm{m}$ was $g_{x, m}$. The specific equation is described as follows:

$$
g_{x, m}=\bar{g}_{x}+\frac{\sum_{a=1}^{k}\left(g_{a, i}-\bar{g}_{a}\right) \operatorname{sim}(x, a)}{\sum_{a=1}^{k} \operatorname{sim}(x, a)}
$$

Wherein, the number of nearest neighbors of learner $\mathrm{x}$ was expressed as $\mathrm{k}$.

- Step 4: descending sort was performed on $g_{x, m}$ and the top K video materials with the highest scores were recommended to learner $\mathrm{x}$.

\subsection{Application of mobile internet-based collaborative knowledge construction teaching course of "Teaching management"}

As shown in Figure 2, in terms of teaching analysis: college students' learning characteristics were acquired before teaching design to know their basic knowledge level and basic ability of education management, thereby clarifying the design focus of learning. In terms of planning and design: to achieve teachers' teaching goals, a suitable teaching management model should be adopted. In terms of teaching evaluation: teachers' goal setting and selection of teaching strategies, as well as students' feedback at class can help teachers improve their teaching approaches, so that every student can acquire their desired knowledge and information, and establish a set of complete collaborative knowledge system, thus facilitating students' evaluation of teacher's teaching system. 


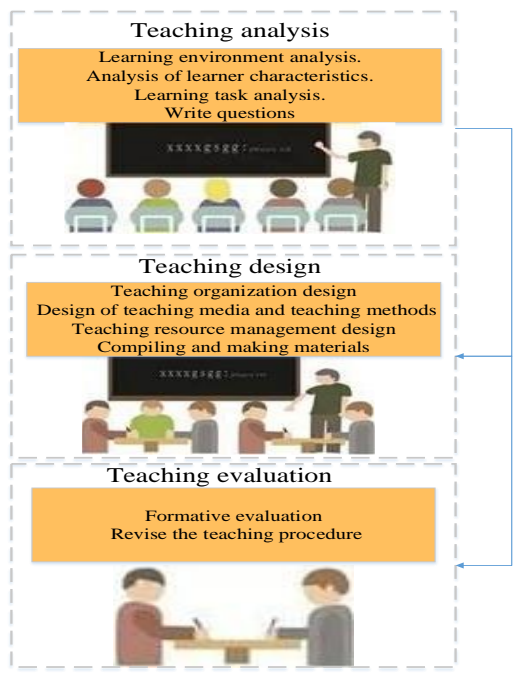

Fig. 2. Teaching process of mobile communication technology-based teaching management course

College students with learning needs can learn collaborative knowledge (Figure 45) via mobile phones, tablets, etc. anytime, anywhere. With the advent of the era of Internet technology big data, because of COVID-19 at the end of 2019, to safeguard the lives of teachers and students, colleges and universities were postponed. In order not to affect students' studies, a variety of online teaching platforms were used for personalized online teaching. The subject of teaching management was no exception. However, due to some teachers' insufficient understanding of the new Internet-based teaching model, online management teaching could not fully manifest its individualization. Without in-depth analysis of student interaction reflected on the platform, the precision teaching could not be fully manifested. In the meantime, in terms of the teacher's teaching model, a relatively complete system has not yet been established, the interaction with students was not enough during teaching, and due to the insufficient data information, the superiority of the Internet teaching model could not be reflected. Under the precondition of Internet resource sharing under the Internet learning model, it is feasible to analyze students' learning needs, and the teacher can explain their own teaching goals, and then analyze students' overall characteristics so as to conduct precise teaching and help students design learning strategies. In the meantime, teachers should help students with poor foundations to analyze learning content, satisfy different students' demands for knowledge in different learning environments. Finally, the teacher's teaching process can be evaluated. 


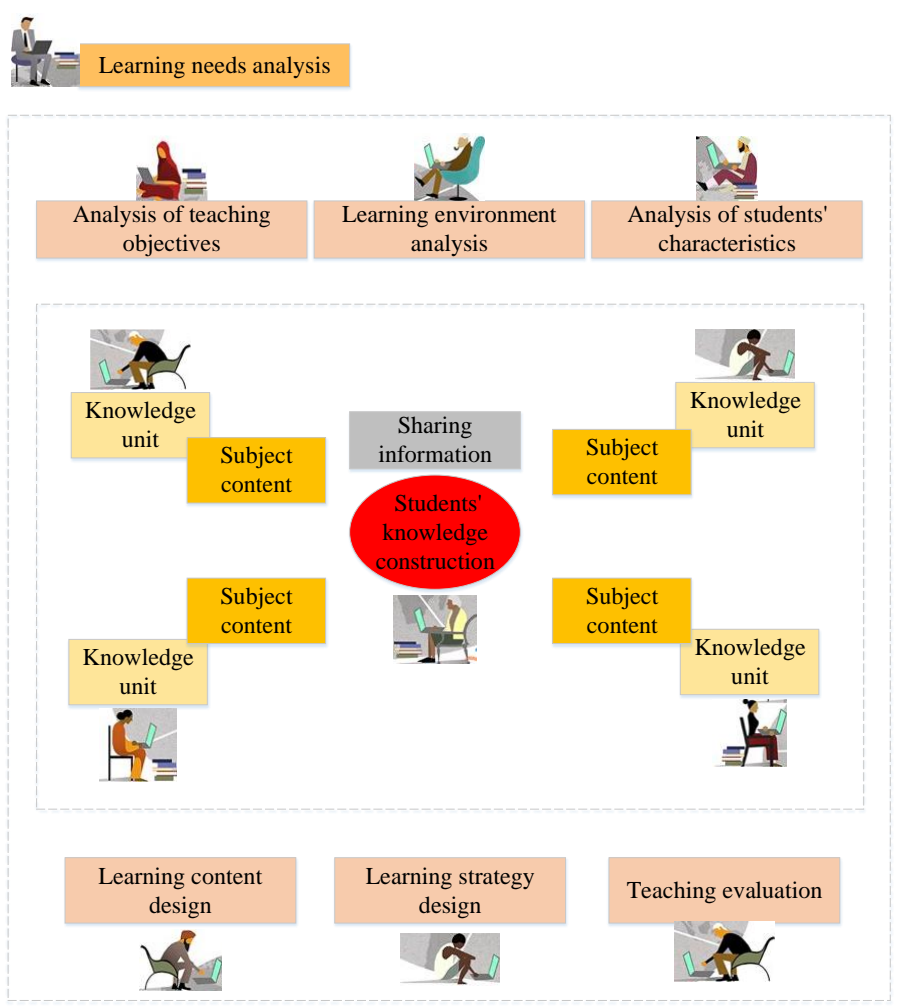

Fig. 3. Internet learning model based on online collaborative knowledge

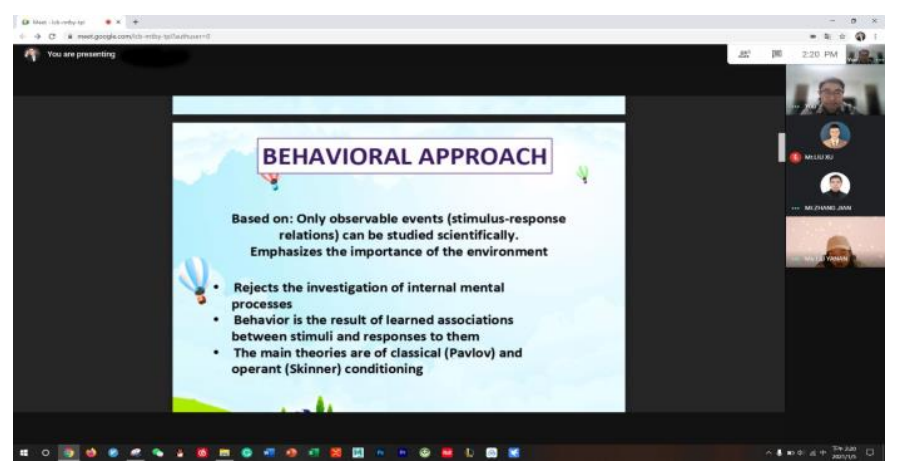

Fig. 4. "Teaching Management" classroom demonstration based on mobile communication technology 


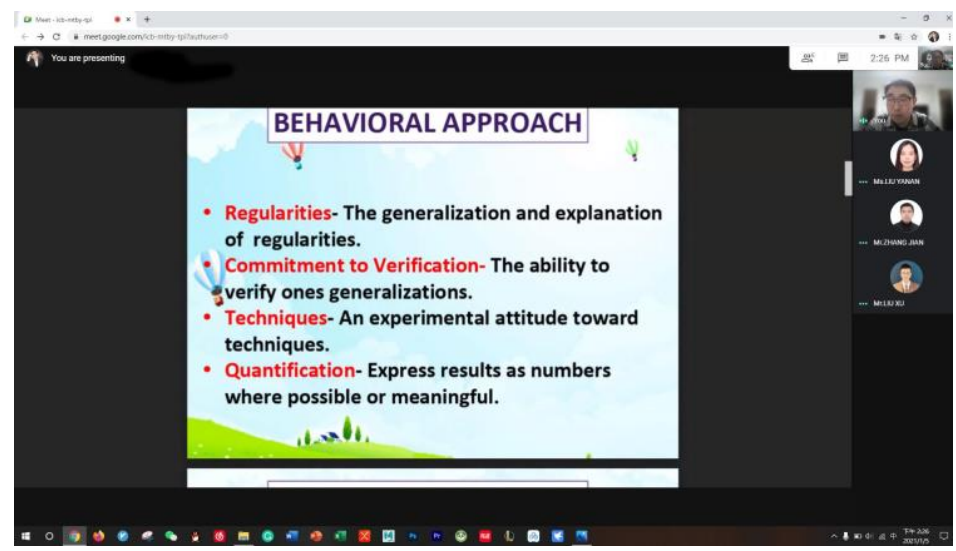

Fig. 5. Demonstration of student classroom discussion section based on mobile communication technology

\section{$4 \quad$ Teaching Example and Effect}

\subsection{Teaching example}

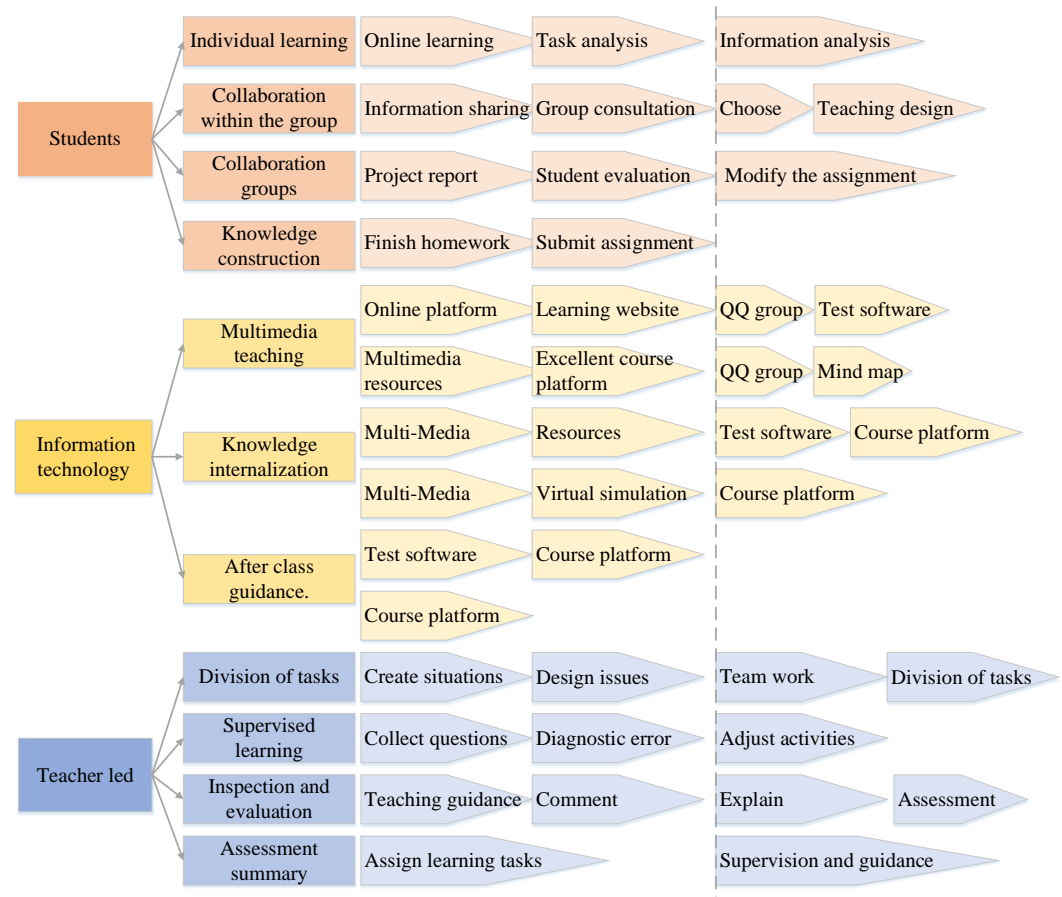

Fig. 6. Network teaching model diagram based on collaborative knowledge construction 


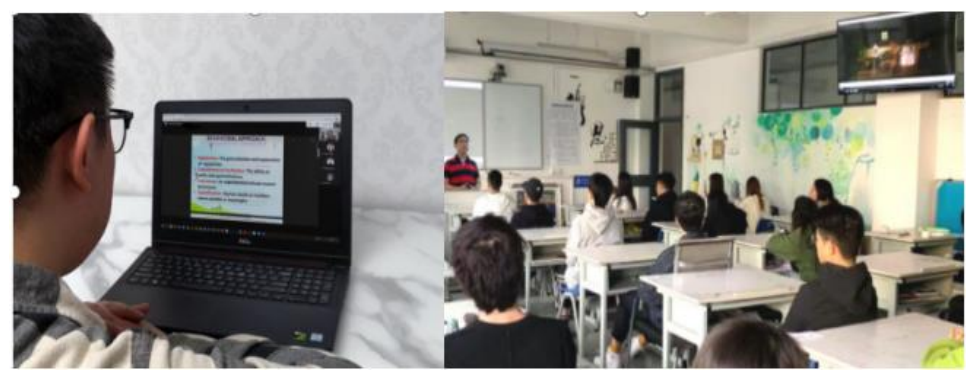

Fig. 7. Network teaching and classroom discussion sections based on collaborative knowledge construction

Figure 6 shows the network teaching model diagram based on collaborative knowledge construction, that is, the main teaching design framework for educational management course on the network platform. Figure 7 shows the scenario of the network teaching section based on collaborative knowledge construction, and the discussion scenario of teachers and students in the classroom.

As shown in figure 6-7, the teacher guided students to conduct a comprehensive design, and the teacher owned full authority to set up courses. Taking the educational management course design as an example, the specific implementation process of the internet-based teaching model based on collaborative knowledge construction was elaborated as follows. (1) Determination of the topic. In the topic selection, the teacher selected topics related to actual production and daily life for students after thorough survey so as to stimulate students' learning interest and creativity. Considering students' accumulation of a certain amount of knowledge in class, it is necessary to choose reasonable scope and difficulty of the topic, so that students can complete the tasks with confidence while obtaining practice and training in this topic.

Determination of grouping and work division. Each group was given one topic, which is not repeated. All topics were announced on the Internet for students to choose, so that students with similar interests can give full play to their initiative and creativity in a group. After the students' selection of the topic, the group leader led group members to conduct further research on the topic, and assigned tasks, including information searching online, text and picture downloading, sample style design, and individual composition of manuscript. The manuscript was evaluated by group members and the final sample text was established in the group for presentation, and everyone was required to complete within the specified time.

Collaborative learning can be conducted via Blog or Wiki. After the students presented their design plans, group members studied and modified, or made use of network resources. The more detailed study and discussion among group members, the more reasonable the results, and the more perfect the work.

Announcement of research results. The members of each group took out their own works for presentation. After fierce discussion and study, an unanimously satisfied work was produced and uploaded to teacher through the Internet, and displayed through Blogs and Wikis. The teacher checked, evaluated, and proposed amendments 
to the result of each group. Each group member discussed and analyzed the teacher's amendments, and then modified the work.

Process assessment, reflection and summary. The assessment of students included self- assessment, mutual assessment among group members, and teacher assessment of the student's performance in the whole process, and the final result was obtained. Such assessment method was conductive to the supervision and control of students' whole learning process, thereby better stimulating students' learning interest and creativity.

\subsection{Teaching effect}

The teaching practice of this model was performed by research team in a university in Shenyang City, Liaoning Province, China from March to June 2020. First, two classes of freshman year education major were selected through cluster sampling method, and students were randomly divided into experimental group and control group. The "Education Management" course was offered in two classes simultaneously. To ensure the scientificity of experiment, the teachers were the same. The experimental group adopted mobile Internet-based collaborative knowledge construction method, and the control group adopted traditional teaching method. Among them, there were 42 students in the experimental class, and 42 valid questionnaires were recovered, with a recovery rate of $100 \%$. There were 39 students in the control class, 39 valid questionnaires were recovered, with a recovery rate of $100 \%$. T-test was performed on students' scores of five questionnaire items to determine whether the learning effect of the experimental class was significantly higher than that of the control class. If the $\mathrm{p}$ value is less than 0.05 , the difference between the two is significant. The test results of students' learning effects in experimental class and the control class are as follows (see Table 1).

Table 1. Comparison of test scores of the study group and the control group

$$
(\bar{x} \pm s, \text { score })
$$

\begin{tabular}{|l|c|c|c|c|c|}
\hline \multicolumn{1}{|c|}{ Group } & Learning initiative & $\begin{array}{c}\text { Academic } \\
\text { record }\end{array}$ & $\begin{array}{c}\text { Creative } \\
\text { thinking }\end{array}$ & $\begin{array}{c}\text { Collaborative } \\
\text { communication }\end{array}$ & $\begin{array}{c}\text { Learning } \\
\text { interest }\end{array}$ \\
\hline Experimental group $(\mathrm{n}=42)$ & $82.3 \pm 7.2^{*}$ & $84.1 \pm 5.4^{*}$ & $81.6 \pm 5.9^{*}$ & $83.4 \pm 6.2^{*}$ & $81.9 \pm 6.7^{*}$ \\
\hline Control group $(\mathrm{n}=39)$ & $76.4 \pm 8.9$ & $77.8 \pm 8.2$ & $72.6 \pm 7.4^{*}$ & $78.5 \pm 7.6^{*}$ & $76.1 \pm 8.1^{*}$ \\
\hline $\mathrm{t}$ & 4.83 & 4.96 & 4.82 & 4.67 & 4.98 \\
\hline
\end{tabular}

Note: * indicates the comparison with the control group, $\mathrm{P}<0.05$

The statistical survey results showed that the average score of the experimental group in terms of learning initiative was higher than that of control group, and the variance was also less than that of control group. The students in experimental group obtained better scores than control group in terms of learning interest, creative thinking ability, and academic performance. Practice showed that the Internet teaching model based online collaborative knowledge could enhance students' learning initiative and creative thinking, improve the insufficient communication between teachers and students in traditional teaching, facilitate collaborative 
communication, and help increase learning interest and teaching effectiveness. The main reasons are as follows: (1) This teaching model allows students to make more flexible choice in learning time and space. The research model is based on mobile communication technology, which is one of its features. As the smartphone processor capabilities are strengthened and wireless network is available, students can access the course website anytime and anywhere via smartphones, obtain accurate push of materials, and communicate with teachers flexibly. Therefore, this teaching model broke the time and space limitations of traditional classroom and online classroom, provided convenience for students to learn anytime and anywhere, and allowed them to maximize information utilization and effectively use their learning time. (2) The teaching model is innovated. Despite project-oriented and task-driven traditional teaching methods, a single model of " theoretical knowledge instruction in class, practical operation after class, and teacher evaluation of results" was often adopted. The teaching model based on collaborative knowledge construction is based on the tasks assigned by the teachers. Before class, students complete tasks through online collaboration and report the results in class. After group evaluation and summary of teacher's evaluation and comments, the task content can be modified in the class. The teacher can provide real-time instruction, and finally the revised results can be presented. The teacher and student can evaluate the work together. During the whole teaching process, students were the main subject, truly manifesting the teaching concept of "educating during learning and learning during teaching", thereby effectively enhancing students' creative thinking and learning interest.

\section{Conclusion}

Mobile-based learning as a new form of learning is developing. There is huge room for development regardless of theoretical research and technological development. But few mobile learning course resources are available for education management course, and the study of $\mathrm{t}$ mobile learning application in education is still at exploration stage. Following conclusions were drawn from the teaching practice:

It was found from teaching practice that mobile Internet-based online collaborative knowledge teaching approach established in this research is feasible and worthy of promotion and reference. It is conducive to enhancing the teaching effect, and strengthening the practical teaching quality of education management, and can substantially improving students' collaborative ability and creative thinking.

Reasonable application of online collaborative knowledge construction approach in education management course can help to develop students' learning autonomy and independent learning. This course was established based on information technology. The visibility of teaching was improved by using animation, video, virtual simulation software, and it fully stimulated students' learning interest.

The mobile learning approach based on the collaborative filtering algorithm proposed in this research can fully exert its convenience, provide abundant resources and guarantee high sharing of resources. The key to ensuring the quality of the mobile learning platform lies in a wealth of high quality of learning resources. Through the 
effective methods of rapid screening and accurate push of learning resources, students' learning efficiency can be improved.

\section{References}

[1] Csapó, B., \& Molnár, G. Online diagnostic assessment in support of personalized teaching and learning: The eDia system. Frontiers in psychology, 2019, vol. 10, pp. 1522. https://doi.org/10.3389/fpsyg.2019.01522

[2] Hua, S., \& Liu, F. A New Hybrid Teaching Model for a Psychology Course. International Journal of Emerging Technologies in Learning, 2021, vol. 16(3), pp. 206-219.

[3] Counte, M. A., Ramirez, B., \& Aaronson, W. Global Healthcare Management Education: Essential Competencies and Major Curricular Challenges. The Journal of health administration education, 2011, vol. 28(3), pp. 227-236.

[4] Shelton, S.A. A Narrative Reflection on Examining Text and World for Social Justice: Combatting Bullying and Harassment with Shakespeare. Journal of Language \& Literacy Education, 2017, vol. 13(1), pp. 1-14.

[5] Rodríguez-Bravo, B., Alvite-Díez, M.L., \& Barrionuevo-Almuzara, L. Trends and models in the consumption of electronic contents: An analysis of the journals most widely used in Spanish universities. The Journal of academic librarianship, 2012, vol. 38(1), pp. 42-59. https://doi.org/10.1016/j.acalib.2011.11.007

[6] Liu, Y. New Discussion on the Design of Teaching Methods for Undergraduate Basic Curriculum in Tourism Management Major_- Taking Tourism Marketing as an Example. Journal of Changchun Normal University, 2009, vol. 28(3), pp. 88-90.

[7] Das, A., Lam, T.K., Thomas, S., et al. Flipped classroom pedagogy: Using pre-class videos in an undergraduate business information systems management course. Education and Training, 2019, vol. 61(6), pp. 756-774. https://doi.org/10.1108/et-06-2018-0133

[8] Strang, K.D. Are student peer assessments reliable? Analysis of a classroom-based management course. International Journal of Education Economics \& Development, 2014, vol. 5(1), pp. 91-112. https://doi.org/10.1504/ijeed.2014.059872

[9] [9] Feng, P.Z., Exploration and practice of computer system customization in school management teaching, 2018, vol. 36, pp. 171

[10] Li, G.C. Case teaching and its application in the course of educational management. South Agricultural Machinery, 2018, vol. 49(20), pp. 216-216.

[11] Tao, Y.P., Xu, C. Research on teaching management platform based on mobile Internet. Computer Programming Skills \& Maintenance, 2015, vol. 23, pp. 48-49.

[12] Zhang, C.H. Teaching practice based on superstar learning -- Taking school management as an example. Journal of Juamjusi Education Institute, 2019, vol. 26(11), pp. 122-123.

[13] Kumar, T.S., Pandey, S. Customization of Recommendation System Using Collaborative Filtering Algorithm on Cloud Using Mahout. Advances in Intelligent Systems and Computing, 2015, vol. 321(19), pp. 39-43. https://doi.org/10.1007/978-3-319-11227-5_1

\section{$7 \quad$ Author}

Sheng Zhang is a Doctor of Education in the Bangkok Thonburi University, Bangkok, Thailand (zhangsheng2025@163.com).

Article submitted 2021-03-15. Resubmitted 2021-04-22. Final acceptance 2021-04-23. Final version published as submitted by the authors. 